\title{
Investigation of Bath/Freeze Lining Interface Temperature Based on the Rheology of the Slag
}

\author{
SAMANT NAGRAJ $\mathbb{1}^{1,2,3}$ MATHIAS CHINTINNE, ${ }^{1}$ MUXING GUO, ${ }^{2}$ \\ and BART BLANPAIN ${ }^{2}$
}

1.-Metallo Belgium N.V, Nieuwe Dreef 33, 2340 Beerse, Belgium. 2.-Department of Materials Engineering, KU Leuven, Kasteelpark 44, 3001 Leuven, Belgium. 3.-e-mail: samant.nagraj@ metallo.com

Freeze lining is a solidified layer of slag formed on the inner side of a watercooled pyrometallurgical reactor, which protects the reactor walls from thermal, physical, and chemical attacks. Because of the freeze lining's high thermal resistance, the reactor heat losses strongly depend on the freeze lining thickness. In a batch process such as slag fuming, the conditions change with time, affecting the freeze lining thickness. Determining the freeze lining thickness is challenging as it cannot be measured directly. In this study, a conceptual framework based on the morphology and microstructure of freeze lining and the rheology of the slag is discussed and experimentally evaluated to determine the freeze lining thickness. It was found that the bath/freeze lining interface lies just below critical viscosity temperature. The growth of the freeze lining is primarily controlled by the mechanical and thermal degradation of the crystals forming at the interface. The bath/freeze lining interface temperature for the measured slag lies in the range of $1035-1070^{\circ} \mathrm{C}$.

\section{INTRODUCTION}

Refractories are heat-resistant materials that are physically and chemically stable at high temperatures. Therefore, they are used to protect furnace walls against thermal, physical, and chemical attacks. Depending on the operating environment, different refractory materials are used. However, refractories are not entirely immune, as slags are highly corrosive towards refractories, quickly decreasing their lifespan. Moreover, replacing refractories can be costly, labor intensive, and time-consuming. ${ }^{1}$ Therefore, in some cases, a liquid-cooled metal wall reactor is used. Due to the cooling, some slag in the reactor solidifies onto the reactor wall, and the solidified layer of slag is called a freeze lining. Because of the slag's low thermal conductivity, the freeze lining takes over the role of a refractory and protects the reactor from thermal, physical, and chemical attacks.

(Received May 12, 2021; accepted October 29, 2021;

published online November 23, 2021)
One of the processes that use a liquid-cooled reactor is a slag fuming furnace, where volatile metals such as $\mathrm{Zn}$ and $\mathrm{Pb}$ are recovered through a reductive treatment. In 2017, Metallo commissioned a batch-type fuming furnace to treat the zinc-rich slags from secondary copper smelter slags. Figure 1 shows a schematic of a wall section of Metallo's submerged plasma slag fuming furnace. The reactor wall has several layers starting from the freeze lining on the molten slag bath side, followed by a steel wall and the cooling water jackets. The reactor heat losses can be calculated by Eq. 1. Since the slag fuming process is endothermic, the degree of reactor heat losses determines the fuming rate and the energy efficiency of the process.

Assuming a constant bath and the bath/freeze lining interface temperature, heat losses are influenced by the convective heat transfer coefficient and the freeze lining thickness (Eq. 1). The freeze lining thickness is defined as the distance between the cold side (attached to the reactor wall) and the hot side (in contact with the slag bath; the bath/freeze lining interface) of the freeze lining.

The heat flux will be low when the freeze lining thickness is high and when the heat transfer coefficient is low, and vice versa. However, in the 


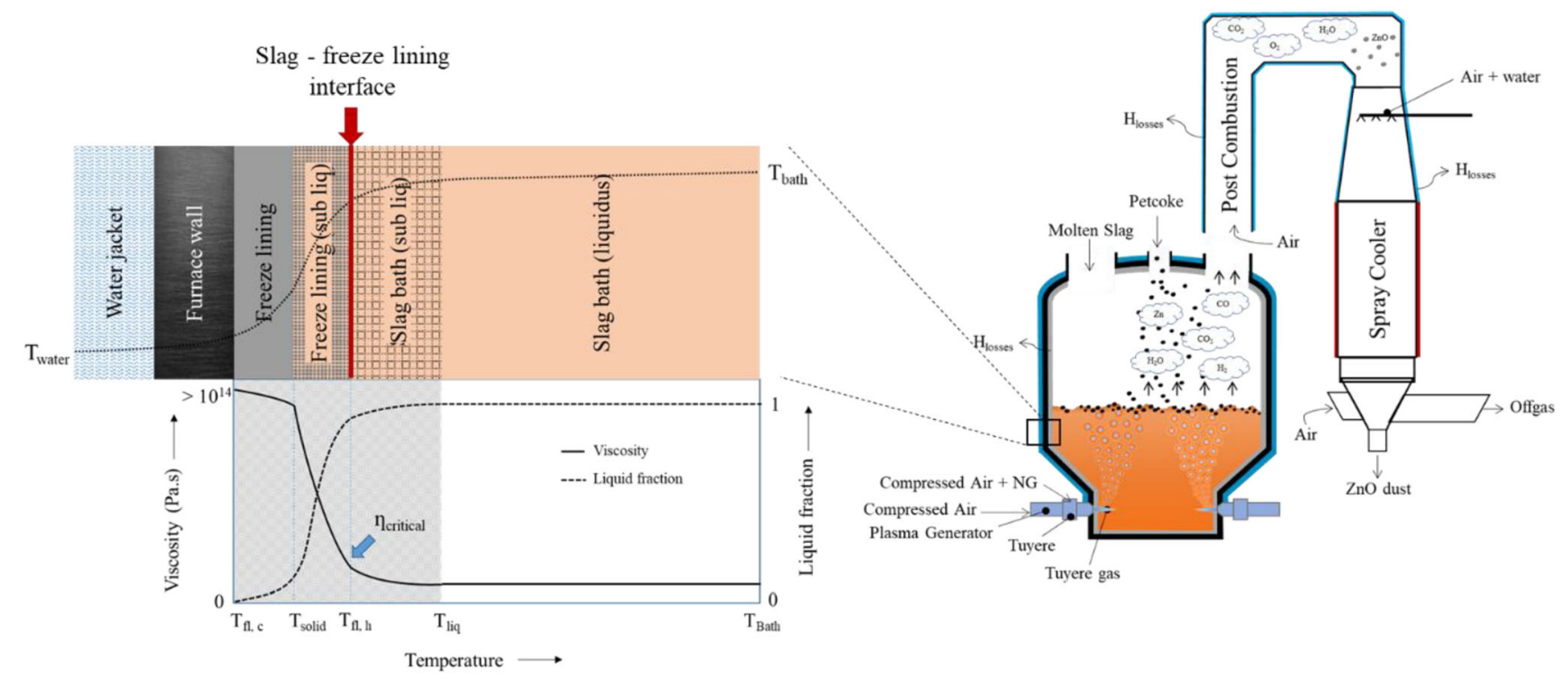

Fig. 1. Schematic of a reactor wall section of Metallo's submerged plasma slag fuming furnace.

slag fuming process, the conditions, such as bath temperature, composition, and agitation, change with time as the $\mathrm{Zn}$ is fumed, affecting the heat losses. Therefore, having accurate values for the convective heat transfer coefficient and freeze lining thickness is indispensable for understanding and ultimately minimizing heat losses to achieve a faster Zn fuming rate.

$$
\dot{\mathrm{q}}=\mathrm{h}_{\mathrm{slag} \rightarrow \mathrm{FL}}\left(\mathrm{T}_{\mathrm{b}}-\mathrm{T}_{\mathrm{i}}\right)=\frac{\mathrm{k}_{\mathrm{f}}}{\mathrm{x}_{\mathrm{f}}}\left(\mathrm{T}_{\mathrm{i}}-\mathrm{T}_{\mathrm{w}}\right)
$$

$\dot{\mathrm{q}}$-heat flux through the wall, $\mathrm{h}_{\mathrm{slag} \rightarrow \mathrm{FL}}$-convective heat transfer coefficient between the slag bath and the freeze lining, $\mathrm{k}_{\mathrm{f}}$-thermal conductivity of the freeze lining, $x_{f}$-freeze lining thickness, $T_{b}$-bath temperature, $\mathrm{T}_{\mathrm{i}}$ - bath/freeze lining interface temperature, and $\mathrm{T}_{\mathrm{w}}$-furnace wall temperature.

To calculate the freeze lining thickness, it is essential to know the bath/freeze lining interface temperature (Eq. 1). Extensive research has been carried out to determine the freeze lining thickness and its relationship to reactor heat losses. Pistorius et al. ${ }^{2}$ and Zietsman et al. ${ }^{3,4}$ developed a 1-D heat transfer model of the Ilmenite process, followed by Wei et al. ${ }^{5}$ for the Hall-Hérault process and Kellogg et al. ${ }^{6}$ for a slag fuming process, to estimate the freeze lining thickness by assuming the bath liquidus temperature as the bath/freeze lining interface temperature. However, this assumption led to an overestimation of the freeze lining thickness, as the models' prediction of the presence of a freeze lining at extreme operating conditions was inaccurate. Solheim et al. ${ }^{7,8}$ realized that the bath temperature and the concentration are not uniform, and that the heat transfer in the reactor is mainly controlled by the convective mass transfer in the bath. Therefore, they included convective and diffusive mass transfer in the model, and assumed the local bath liquidus temperature (i.e., the bath/ freeze lining interface's liquidus temperature close to the freeze lining) to be the bath/freeze lining interface temperature. However, this approach is inherently flawed as it makes Eq. 1 invalid for process temperatures below liquidus.

Microstructures of freeze lining for a range of slag/salt systems revealed the existence of a subliquidus boundary layer..$^{9-11}$ To explain the observed subliquidus interface temperature, Fallah-Mehrjardi et al. ${ }^{11}$ proposed a mechanism where the slag continuously solidifies and melts at the bath/freeze lining interface. However, the solidification rate directly impacts the mass transfer rate, influencing the microstructure and the size of the crystals. ${ }^{10}$

Crivits et al. ${ }^{12}$ extended Fallah-Mehrjardi et al.'s ${ }^{11}$ research by studying the influence of heat and mass transfer and elementary reaction steps on the freeze lining, and found that the bath/freeze lining interface temperature depends on the nucleation and growth rate of the primary phase rather than on the bath temperature. For bath/freeze lining interface temperatures below the liquidus temperature, increased bath agitation resulted in higher steady-state freeze lining hot face temperatures, and a microstructure with a higher solid volume fraction at the hot face. In contrast, increased bath viscosity decreased the steady-state freeze lining hot face temperature.

In the subliquidus zone, the solid fraction of the slag increases when the temperature is decreased from the melting point until it solidifies completely. Rheological studies on slags have shown that slag transition from a liquid-like regime (viscosity dominated by liquid phase) to a solid-like regime (viscosity dominated by solid phase) occurs in the 
subliquidus region. The slag's viscosity slowly increases as the temperature decreases, and the solid fraction increases. It then increases abruptly at a temperature called the critical viscosity temperature, as the slag acts like a solid rather than a mushy liquid that can still flow easily. ${ }^{13}$

We hypothesize that the critical viscosity temperature is the bath/freeze lining interface temperature. This hypothesis has been experimentally evaluated to determine the bath/freeze lining interface temperature by connecting the rheology of the slag with the freeze lining's microstructure. Viscosity measurements were performed on copper slags to determine the critical viscosity temperature. Equilibrium quenching tests were carried out to find the solid volume fraction at and near the critical viscosity temperature. To verify the proposed hypothesis of viscosity dependence on the bath/freeze lining interface temperature, a laboratory-scale cold finger technique was used to produce freeze lining samples. Microstructure and composition changes across the freeze lining thickness have been studied to identify the bath/freeze lining interface and compared with the solid fraction measured at the critical viscosity temperature. If the hypothesis holds, the solid fraction measured at the bath/freeze lining interface will equal the solid fraction measured at the critical viscosity temperature.

\section{EXPERIMENTAL}

\section{Material}

The slag bath composition changes continuously during the zinc fuming process, affecting the bath/ freeze lining interface. Therefore, three slags were selected with varying $\mathrm{Zn}$ content. Slag A used in this study is an industrial slag from the secondary copper smelter at Metallo Belgium. $\mathrm{ZnO}$ was added to Slag A to obtain Slag B and Slag C with $\mathrm{ZnO}$ contents $8 \mathrm{wt} \%$ and $11 \mathrm{wt} \%$, respectively, so that only the $\mathrm{ZnO}$ content is varied while the remaining slag components' relative content remained constant. The composition of the three slags is shown in Table I.

Before the experimental study, an equilibrium test was conducted between the slag and a crucible for $6 \mathrm{~h}$ to choose a crucible material that does not dissolve in the slag. Alumina crucibles showed no apparent dissolution in the slag. Upon performing the chemical analysis described in "Sample Analysis and Characterization" section, it was found that the alumina content has increased by an average of 0.4 wt\% at the interface. Therefore, alumina crucibles and spindles were chosen for the study.

\section{Viscosity Measurements}

The viscosity measurements were carried out on slags A and B using an Anton Paar FRS 1800 Rheometer (see supplementary Fig. S1) ${ }^{14}$ in an argon atmosphere. No viscosity measurements on slag $\mathrm{C}$ were made due to technical issues with the rheometer. An alumina spindle and crucible were used for the measurements. The slags were heated to $1250^{\circ} \mathrm{C}$ and equilibrated for $30 \mathrm{~min}$. The spindle was immersed in the slag and rotated at maximum speed (143 rpm) for $30 \mathrm{~min}$ for homogenization. The spindle rotation speed was decreased to the desired value and held until the measured viscosity stabilized. The viscosity measurements were made in a continuous cooling regime $\left(1^{\circ} \mathrm{C} / \mathrm{min}\right)$ from $1250^{\circ} \mathrm{C}$ and at three spindle speeds $(90,60$, and $30 \mathrm{rpm})$ for slag A and $90 \mathrm{rpm}$ for slag B until the temperature at which the spindle reached a set torque limit of $200 \mathrm{mNm}$.

\section{Equilibrium Quenching Tests}

To determine the solid volume fraction of the slags at and near the critical viscosity temperature, the equilibrium quenching tests were carried out in a vertical tube furnace in an argon atmosphere at $1200^{\circ} \mathrm{C}, 1100^{\circ} \mathrm{C}, 1090^{\circ} \mathrm{C}, 1080^{\circ} \mathrm{C}, 1070^{\circ} \mathrm{C}$. and 1060 ${ }^{\circ} \mathrm{C}$. The slag sample was melted at $1250^{\circ} \mathrm{C}$ in an alumina crucible for $1 \mathrm{~h}$. The sample temperature was lowered to the desired temperature, equilibrated for $1 \mathrm{~h}$, and quenched in the water. The quenched samples were prepared for microstructural analysis.

\section{Cold Finger Freeze Lining Tests}

The cold finger freeze lining tests were carried out in a vertical tube furnace (see Fig. 2). The slag was melted at $1200^{\circ} \mathrm{C}$ in an alumina crucible in an argon atmosphere. The cold finger was circulated with nitrogen gas at $3800 \mathrm{l} / \mathrm{h}$ and was submerged in the molten slag for $1 \mathrm{~h}, 2 \mathrm{~h}$, or $4 \mathrm{~h}$, followed by quenching in water. For the tests with the rotating crucible, a motor was used, located at the bottom of the furnace. The freeze lining deposits were collected and prepared for microstructural analysis.

Table I. Composition of slags

\begin{tabular}{|c|c|c|c|c|c|c|c|c|}
\hline Wt\% & $\mathrm{FeO}$ & $\mathrm{SiO}_{2}$ & $\mathbf{A l}_{2} \mathbf{O}_{3}$ & $\mathrm{CaO}$ & $\mathrm{ZnO}$ & $\mathbf{P b O}$ & $\mathrm{Cu}_{2} \mathbf{O}$ & $\mathrm{Cr}_{2} \mathrm{O}_{3}$ \\
\hline Slag A & 57.70 & 30.79 & 2.63 & 0.63 & 5.38 & 1.03 & 0.85 & 0.98 \\
\hline Slag B & 56.11 & 29.94 & 2.56 & 0.61 & 8.00 & 1.00 & 0.83 & 0.95 \\
\hline Slag C & 54.28 & 28.96 & 2.48 & 0.59 & 11.00 & 0.97 & 0.80 & 0.92 \\
\hline
\end{tabular}


(a) Experimental setup

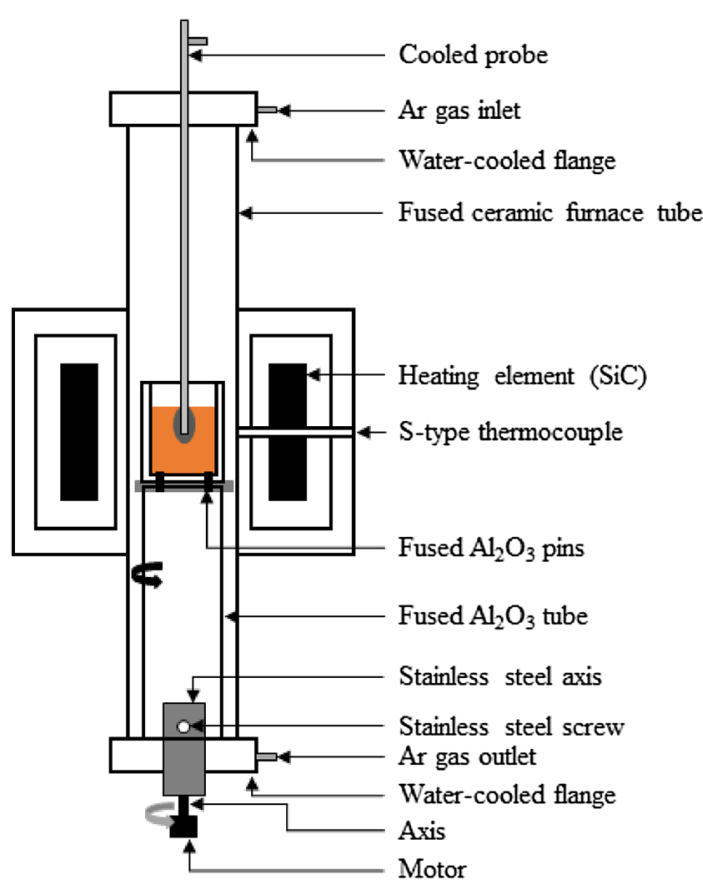

(b) Cooled probe

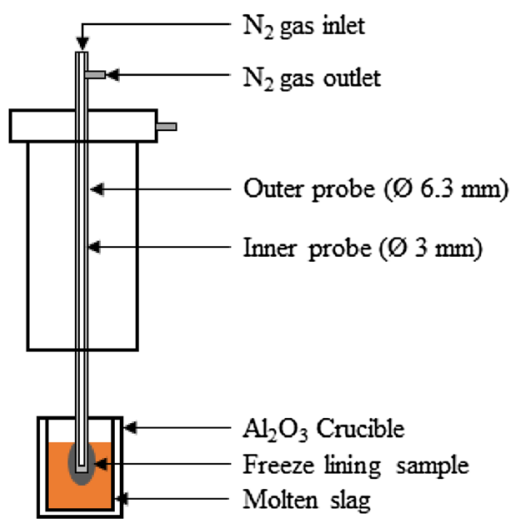

Fig. 2. Cold finger freeze lining test setup: (a) vertical tube furnace, (b) cold finger.

\section{Sample Analysis and Characterization}

The quenched samples and the freeze lining sample deposited on the cold finger were collected and embedded in an epoxy resin. The samples were polished with carbide paper and diamond paste, and a 2-nm platinum coating was applied. The samples were analyzed for composition and microstructural changes using a Philips XL30 ESEM FEG equipped with an energy dispersive x-ray detector (EDAX). The accelerating voltage and the spot size were set as $15 \mathrm{kV}$ and 4 , respectively. A point analysis was used to measure the composition of the solid and liquid phases, whereas an area analysis is used to obtain an average sample composition (see Fig. 6, below). ImageJ software was used to digitally analyze the microstructural images to obtain the solid fraction data using the image processing technique described by Fiji. ${ }^{15}$ To obtain statistically significant data, at least three microstructural images were processed per sample. Furthermore, each image was randomly divided into several smaller sections to obtain the distribution of solid fraction data within an image in contrast to the overall image.

\section{RESULTS AND DISCUSSIONS}

\section{Viscosity Measurements}

The viscosity of Slag A and slag B were measured during continuous cooling from $1250^{\circ} \mathrm{C}$ until the temperature at which a set torque limit of the spindle of $200 \mathrm{mNm}$ was reached. The measurements were conducted at three different spindle speeds (30,60, and $90 \mathrm{rpm}$ ) for slag A and 90 rpm for slag B. Figure 3 shows the viscosities of slags A and B with respect to temperature. Slag A showed shear-thinning behavior, as the viscosity of the slag decreased with increasing shear rate. This is typical for copper slags. ${ }^{16}$ However, the applied shear rate does not have a significant effect on the viscosity. The viscosity of slags $A$ and $B$ initially increased slowly and then, from $1080^{\circ} \mathrm{C}$, more rapidly, indicating a transition from a solid-like regime to a liquid-like regime. The critical viscosity temperature was, therefore, equal to $1080^{\circ} \mathrm{C}$.

\section{Equilibrium Quenching Tests}

The equilibrium quenching tests were performed on the slag samples A, B, and C at $1200^{\circ} \mathrm{C}, 1100^{\circ} \mathrm{C}$, $1090^{\circ} \mathrm{C}, 1080^{\circ} \mathrm{C}, 1070^{\circ} \mathrm{C}$, and $1060^{\circ} \mathrm{C}$. Figure 4 shows the microstructures of quenched samples of slag A. The SEM-EDAX analysis of the quenched samples revealed that $\mathrm{FeO}$ and $\mathrm{SiO}_{2}$ combined to form fayalite crystals, and that $\mathrm{FeO}, \mathrm{ZnO}, \mathrm{Al}_{2} \mathrm{O}_{3}$, and $\mathrm{Cr}_{2} \mathrm{O}_{3}$ combined to form spinel crystals. The light gray color is the crystalline phase in which the laminar grains are fayalite crystals, and the spheroidal grains are Fe-Al-Zn-Cr-O spinel crystals. The dark gray color is the slag matrix (glass phase).

At $1200^{\circ} \mathrm{C}$, the slag is nearly molten with a few spinel crystals (see Fig. 4a). As the temperature decreased, the crystal fraction in the samples increased (see Fig. 4a-g). The fayalite crystal size grew longitudinally, and the crystals appeared to be 

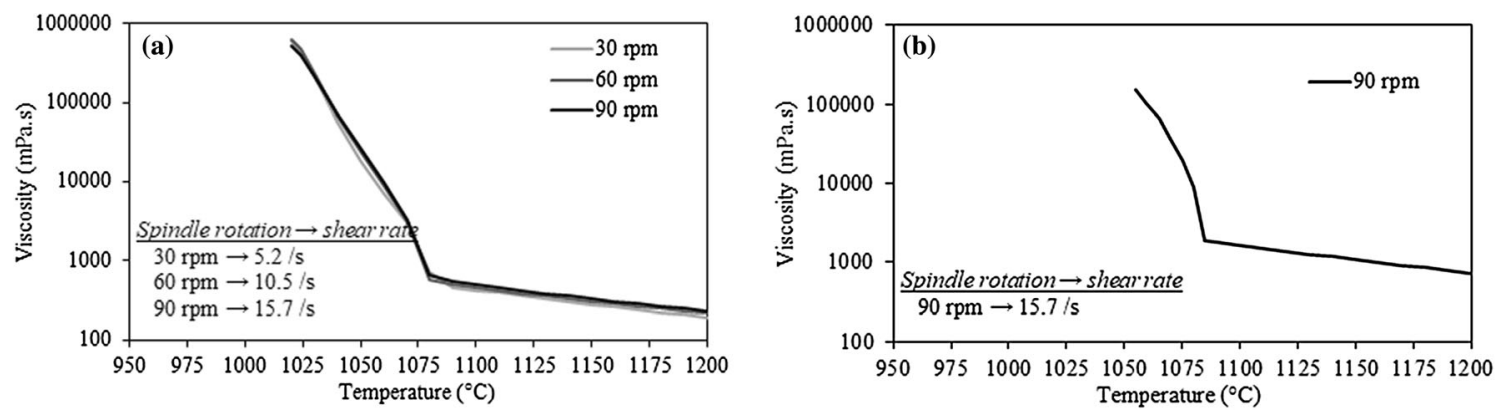

Fig. 3. The viscosity of (a) slag A and (b) slag B with respect to temperature at different spindle speeds.

randomly oriented with respect to each other, whereas the spinel crystal size remained the same. However, from $1080^{\circ} \mathrm{C}$, the fayalite crystals grew further, and the longitudinal shape of the crystals allowed themselves to orient parallel to each other, while the distance between the fayalite crystals decreased (see Fig. 4d-g). The liquid slag between the crystals solidified and connected to the neighboring crystals to form a solid network. The abrupt viscosity increase observed during the viscosity measurements is essentially due to the formation of a solid network.

According to the studies on the non-Newtonian behavior of solid-bearing slags, when the slag is subjected to a sufficient shear rate, the hydrodynamics of the liquid slag contributes to the shearthinning behavior by orienting the crystals in the flow direction. ${ }^{17}$ Since the fayalite crystals, due to their elongated shape, readily oriented themselves parallel to each other as they grew larger without being subjected to an external shear rate, slag A did not show a significant shear thinning behavior during the viscosity measurements (see Fig. 3a).

The SEM images of the quenched samples were analyzed in ImageJ software to quantify the solid fraction. Figure 5 shows the crystal fractions of slags $\mathrm{A}, \mathrm{B}$, and $\mathrm{C}$ at different temperatures. The solid fraction in all the slag samples increased as the temperature decreased. However, at $1080^{\circ} \mathrm{C}$, a large standard deviation in the solid fraction was observed. The microstructure images of slag A at $1080^{\circ} \mathrm{C}$ show that some regions were solidified and formed a solid network, and some regions were still liquid with fayalite and spinel crystals floating far from each other (see Fig. 4d and e). However, below this temperature (see Fig. $4 \mathrm{f}$ and g), all the crystals agglomerated and formed a solid network, suggesting that, at $1080^{\circ} \mathrm{C}$, slags $\mathrm{A}$ and $\mathrm{B}$ transitioned from a liquid dominant regime to a solid dominant regime. This is in good agreement with the slag viscosity measurement results in Fig. 4, where the viscosity of slags increases rapidly with further cooling from $1080^{\circ} \mathrm{C}$. The solid volume fractions of the slags $\mathrm{A}, \mathrm{B}$, and $\mathrm{C}$ at the critical viscosity temperature were found to be $39.69 \pm 8.44 \%$, $41 \pm 4.31 \%$, and $41 \pm 1.8 \%$, respectively.
The viscosity of the slag below liquidus primarily depends on the cooling rate and the shape, size, and interactions between the crystals, which is a function of slag composition. ${ }^{18}$ During solidification, a small part of the $\mathrm{Zn}$ in the samples was distributed between the spinel phase, which did not grow as the temperature decreased, while the rest remained in the slag (glass) phase. Since Zn-containing crystals did not contribute to the agglomeration process, the $\mathrm{Zn}$ content of the slag showed no effect on the critical viscosity temperature. Therefore, it is evident that the critical viscosity temperature does not change with the $\mathrm{Zn}$ content in the measured slag system.

\section{Cold Finger Freeze Lining Tests}

Freeze lining tests were conducted to determine the influence of the immersion time and the spindle rotation speed on the freeze lining thickness. The average thickness of the freeze lining samples of slag A formed when the cold finger was immersed for 1,2 , and $4 \mathrm{~h}$, respectively, was $12.5 \pm 0.7 \mathrm{~mm}$, suggesting that they reached an equilibrium thickness in less than an hour (see supplementary Fig. S2a). However, the average thickness of the freeze lining samples of slag A formed when the cold finger was immersed for $1 \mathrm{~h}$, and, when the crucible was rotated at 30,60 , and $90 \mathrm{rpm}$, decreased from $8.9 \mathrm{~mm}$ to $5.1 \mathrm{~mm}$ with increasing crucible rotation speeds from $30 \mathrm{rpm}$ to $90 \mathrm{rpm}$ (see supplementary Fig. S2b). Further cold finger freeze lining tests were conducted on slags $\mathrm{B}$ and $\mathrm{C}$ to study the influence of varying $\mathrm{Zn}$ content in the slag on the freeze lining thickness and the bath/freeze lining interface temperature.

The freeze lining samples were cut across the thickness to perform SEM imaging (see supplementary Fig. S3). Figure 6a shows the microstructures of the freeze lining samples of slag A tested at $90 \mathrm{rpm}$ with $1 \mathrm{~h}$ equilibration at $1200^{\circ} \mathrm{C}$. The light gray colored laminar grains are fayalite crystals, and the dark gray color is the liquid slag (glass phase). The crystals on the freeze lining samples vary in size from the cold side (attached to the cold finger) to the hot side (close to the slag bath). The cold side of the sample has very fine crystals, as the 

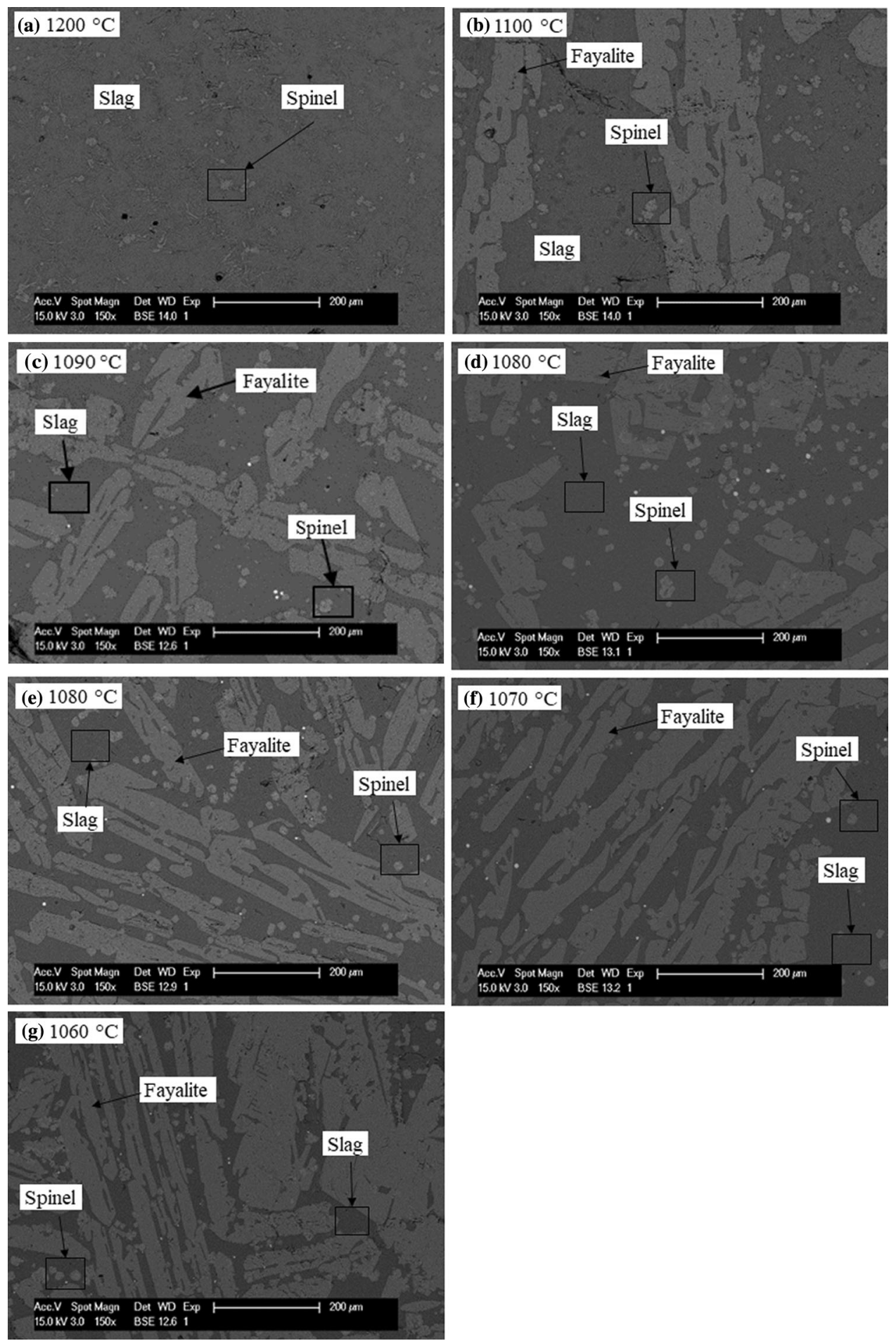

Fig. 4. Microstructures of slag A samples quenched at (a) $1200^{\circ} \mathrm{C}$, (b) $1100^{\circ} \mathrm{C}$, (c) $1090^{\circ} \mathrm{C}$, (d, e) $1080^{\circ} \mathrm{C}$, (f) $1070^{\circ} \mathrm{C}$, and (g) $1060^{\circ} \mathrm{C}$.

slag solidified immediately with a large undercooling degree when the cold finger was immersed in the slag bath. The crystals gradually became larger towards the hot side. However, finer crystals were observed close to the hot face only when the crucible was rotated at $60 \mathrm{rpm}$ and $90 \mathrm{rpm}$.

Figure $6 \mathrm{~b}$ and $\mathrm{c}$ shows the solid fraction and the composition measured across the thickness of the samples in the regions marked in Fig. 6a. The solid fraction along the freeze lining thickness increased slowly from $65 \%$ from the cold side to the hot side and peaked at $73 \%$; however, it decreased rapidly to $55 \%$. The microstructure of the freeze lining in Fig. 6 a shows that the crystal size became finer from the peak to the hot face. It is logical to assume that the freeze lining until the peak is stable. It is then 
thermally affected, where the interface moves depending on the process conditions. The $\mathrm{FeO}$ content in the freeze lining has dropped by an average of $9 \mathrm{wt} \%$ and $\mathrm{Al}_{2} \mathrm{O}_{3}$ increased by $10 \mathrm{wt} \%$ compared to the slag bath composition. However, the freeze lining composition remained more or less constant throughout the thickness. The $\mathrm{FeO}$ combined with $\mathrm{SiO}_{2}$ to form $\mathrm{Fe}_{2} \mathrm{SiO}_{4}$ crystals, whereas the $\mathrm{ZnO}, \mathrm{Al}_{2} \mathrm{O}_{3}$, and $\mathrm{CaO}$ remained in the glass phase. The $\mathrm{FeO}$ content in the slag dropped to 31 wt\% to form fayalite and spinel crystals, whereas the $\mathrm{Al}_{2} \mathrm{O}_{3}$ and $\mathrm{SiO}_{2}$ content in the glass phase increased significantly. A similar trend in the distribution of solid fraction and the composition across the freeze lining thickness was observed in the remaining freeze lining samples.

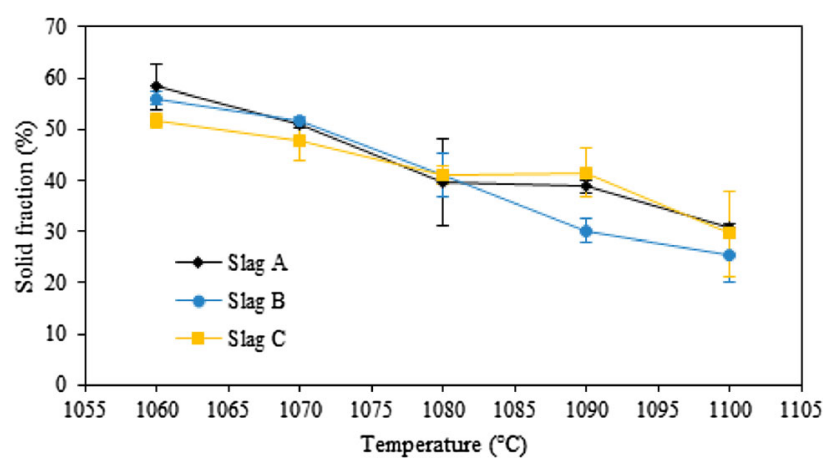

Fig. 5. Solid fraction of the quenched samples with respect to temperature.
Figure 7a shows the freeze lining thickness at different crucible rotation speeds as a function of $\mathrm{Zn}$ content in the slags. The thickness of the freeze lining samples was affected by the crucible rotation speed. When the crucible was stationary and when it rotated at $30 \mathrm{rpm}$, the thickness decreased linearly with increasing $\mathrm{Zn}$ content from slag A (5.4 wt\% $\mathrm{Zn}$ ) to slag $\mathrm{C}$ (11 wt\% $\mathrm{Zn}$ ) by $4.2 \mathrm{~mm}$ and 2.6 $\mathrm{mm}$, respectively. However, when the crucible was rotated at $60 \mathrm{rpm}$ and $90 \mathrm{rpm}$, the thickness decreased with increasing $\mathrm{Zn}$ content by $2 \mathrm{~mm}$ and $2.1 \mathrm{~mm}$, respectively, from slag $\mathrm{A}(5.4 \mathrm{wt} \% \mathrm{Zn})$ to slag B (8 wt\% $\mathrm{Zn})$ and then increased by $2 \mathrm{~mm}$ and $1.7 \mathrm{~mm}$, respectively, from slag B (8 wt\% $\mathrm{Zn})$ to slag C (11 wt\% Zn). It appears from Fig. S3 and Fig. 7a that the $\mathrm{Zn}$ content is affecting the freeze lining thickness, contradicting the evidence found in "Equilibrium Quenching Tests" section. It was evident from the observed microstructures of the freeze lining samples, and the solid fraction distribution across their thickness, that factors such as the hydrodynamics of the liquid slag and the interactions between the crystals and the liquid slag are playing a role in the freeze lining growth.

When a solid-bearing slag with a shear thinning behavior is subjected to a sufficient shear rate, the weak crystals inside the solid network gradually break up into isolated particles, affecting the morphology. ${ }^{17}$ From the SEM images of the freeze lining samples (see supplementary Fig. S3), it is clear that the crystals' size at the hot face of the freeze lining varied with crucible rotation speed. Large crystals were observed at the hot face when the crucible was

(a)

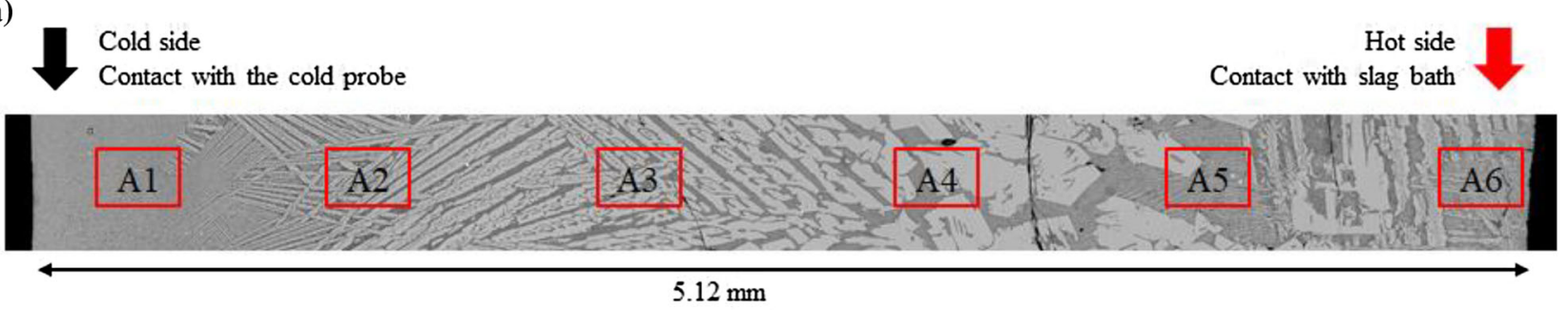

(b)

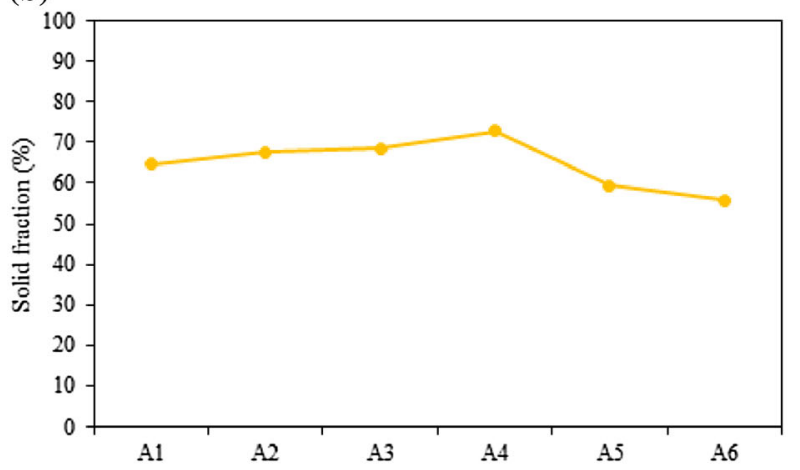

(c)

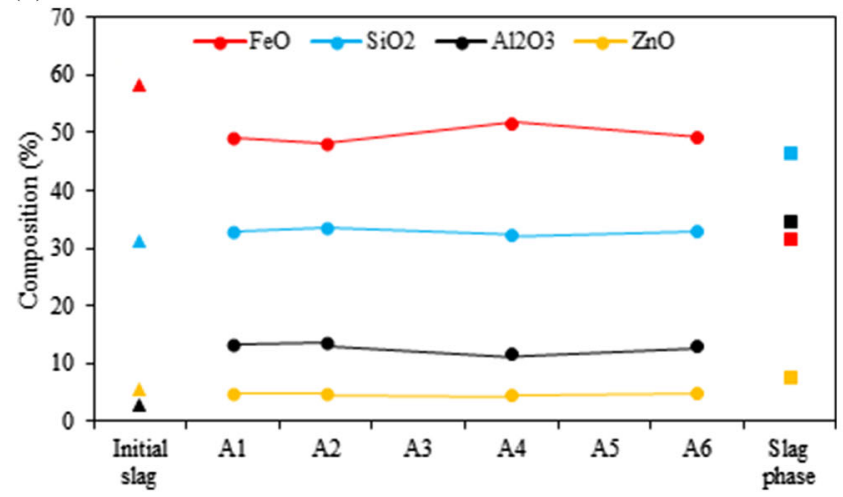

Fig. 6. (a) The SEM image, (b) the solid fraction, and (c) the composition of the freeze lining sample of slag A tested at $90 \mathrm{rpm}$ under $1200^{\circ} \mathrm{C}$ for 1 h. 

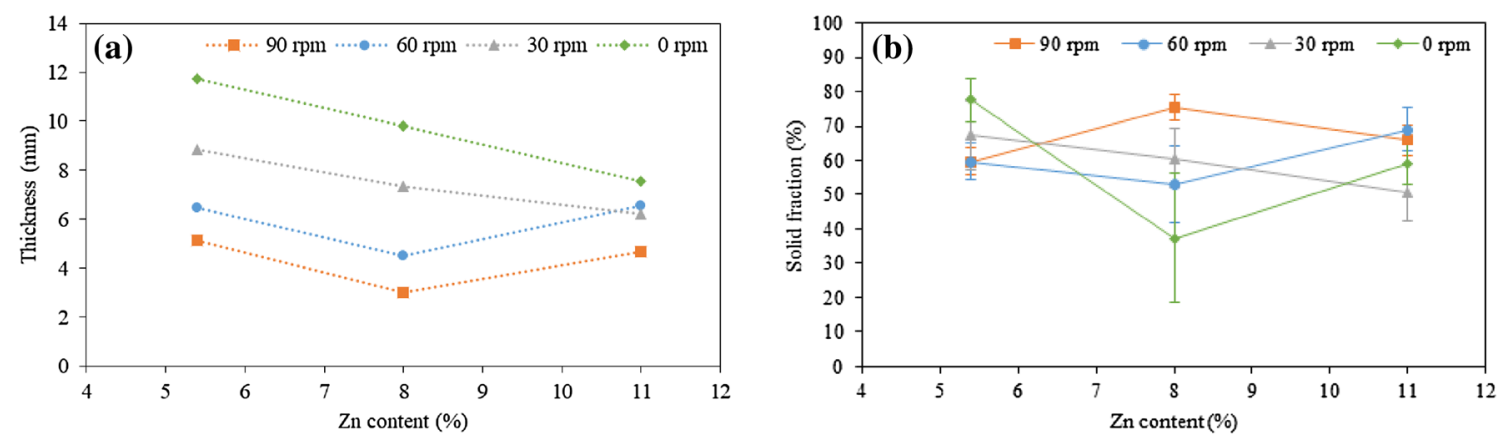

Fig. 7. (a) The freeze lining thickness and (b) the solid fractions of the freeze lining samples of slag $A(5.4 \mathrm{wt} \% \mathrm{Zn}$ ), slag B (8 wt\% Zn) and slag C $(11 \mathrm{wt} \% \mathrm{Zn})$ at the hot face equilibrated at $1200^{\circ} \mathrm{C}$ for $1 \mathrm{~h}$ at crucible rotation speeds of 30,60 , and $90 \mathrm{rpm}$.

stationary and when it was rotating at $30 \mathrm{rpm}$, suggesting that the crystals stayed intact within the solid network. Furthermore, the temperature close to the hot face was high enough and the growth time was long enough for the crystals to grow larger. The heat transfer rate was low, due to low convective heat transfer, resulting in a larger freeze lining thickness. However, at high crucible rotation speeds (60 rpm and $90 \mathrm{rpm}$ ), due to the high shear rate, the loose crystals forming at the bath/freeze lining interface were removed into the slag bath, while bringing the new crystals to the interface. Due to the dynamic exchange of crystals at the interface, the crystal size remained small. Additionally, due to the high crucible rotation speeds, the convective heat transfer increased, increasing the temperature at the hot face of the freeze lining. As a result, the freeze lining thickness decreased, and the bath/ freeze lining interface moved to a new location, where the bath/freeze lining interface temperature is equal to or less than the critical viscosity temperature. Therefore, the freeze lining thickness was smaller with relatively finer crystals at the hot face.

Figure $7 \mathrm{~b}$ shows the critical solid fraction at the hot face of the freeze lining samples of slags A, B, and $\mathrm{C}$ equilibrated at $1200^{\circ} \mathrm{C}$ for $1 \mathrm{~h}$ at crucible rotation speeds of 30,60 , and $90 \mathrm{rpm}$ measured using ImageJ software. The solid fraction at the hot face of the freeze lining does not follow a trend with varying $\mathrm{Zn}$ content. However, the average solid fraction of the slags A, B, and C at the hot face of the freeze lining increased with crucible rotation speed (see supplementary Fig. S4). It is logical to say that, at high crucible rotation speeds, newly formed crystals in the slag bath arrive at the interface and agglomerate, leading to a finer but densely packed crystal structure. However, at low crucible rotation speeds, the growth of the crystals is limited due to a slow mass transfer rate. Since no fresh slag nor newly formed crystals are arriving at the interface from the slag bath, the crystals grow in size as much as possible in the existing slag at the interface, leaving the remaining slag between the crystals. Since the $\mathrm{Zn}$ content of the slag does not influence the critical viscosity temperature, the solid fraction, and the freeze lining growth in the studied range, the averaging of solid fractions of the slags $\mathrm{A}, \mathrm{B}$, and $\mathrm{C}$ at the hot face of the freeze lining is justified.

According to the proposed hypothesis, the bath/ freeze lining interface temperature is equal to the critical viscosity temperature. It was found that the critical viscosity temperature of the measured slags is $1080^{\circ} \mathrm{C}$, and that it does not change when the $\mathrm{Zn}$ content of the slag is varied, as $\mathrm{Zn}$ is not participating in the network formation. From the equilibrium quenching tests, the average solid fraction of the slags $\mathrm{A}, \mathrm{B}$, and $\mathrm{C}$ at the critical viscosity temperature was found to be $41 \pm 4.8 \%$. Concurrently, from laboratory-scale freeze lining tests, the average solid fractions at the hot face of the freeze lining of slags $\mathrm{A}, \mathrm{B}$, and $\mathrm{C}$ at $0,30,60$, and $90 \mathrm{rpm}$ were found to be $58 \pm 10.1 \%, 59 \pm 5.5 \%, 61 \pm 4.9 \%$, and $67 \pm 3.9 \%$, respectively. In contrast to the solid fraction obtained from the equilibrium quenching tests at critical viscosity temperature $\left(1080^{\circ} \mathrm{C}\right)$, the solid fraction measured at the hot face of the freeze lining samples were higher, indicating that the hot face temperature of the freeze lining is lower than the critical viscosity temperature. By extrapolating the solid fraction data in Fig. 5, it was found that the bath/freeze lining interface temperature range from $1035^{\circ} \mathrm{C}$ to $1070^{\circ} \mathrm{C}$.

The evidence gathered from the freeze lining tests also showed that $\mathrm{Zn}$ does not influence the freeze lining growth, as it is primarily controlled by the mechanical and thermal degradation of the crystals forming at the bath/freeze lining interface. The solid fractions at the hot face of the freeze lining interface did not follow a trend for the reasons mentioned above (see Fig. 7b). However, when the solid fraction values of slags $\mathrm{A}, \mathrm{B}$, and $\mathrm{C}$ at the hot face are averaged, it was found that the solid fraction increased with shear rate (see supplementary Fig. S4). The shear rate also affected the morphology of the crystals found at the interface, where finer crystals were observed at high shear rates, and vice versa. Based on the empirical evidence, it can be inferred that the slag bath/freeze lining interface temperature is close to the critical viscosity 
temperature. However, the interface temperature decreases when the shear rate is increased. In order to precisely identify the slag bath/freeze lining interface, the relationship between the shear rate, mass transfer rate, morphology, and the solid fraction needs to be further investigated.

\section{CONCLUSION}

From viscosity measurements, it was found that the copper slag's viscosity increases abruptly at a critical temperature of $1080^{\circ} \mathrm{C}$, where it transitions from a liquid-like regime to a solid-like regime, and that the critical viscosity temperature does not change with $\mathrm{Zn}$ content. The microscopic analysis of the equilibrium quenching test samples showed the crystals agglomerating at the critical viscosity temperature, and that the solid fraction at this temperature was $41 \pm 4.8 \%$. Concurrently, the microscopic analysis of the freeze lining samples revealed that the solid fraction at the freeze lining samples' hot face depends on the hydrodynamics of the liquid slag and the interactions between the crystals and the liquid slag at the interface. The average solid fraction at the hot face of the freeze lining was $58 \pm 10.1 \%, 59 \pm 5.5 \%, 61 \pm 4.9 \%$, and $67 \pm 3.9 \%$ at $0,30,60$, and $90 \mathrm{rpm}$, respectively, and the bath/freeze lining interface temperature lies in the range of $1035-1070^{\circ} \mathrm{C}$, which is less than the critical viscosity temperature.

\section{ACKNOWLEDGEMENT}

This project has received funding from the European Union's EU Framework Programme for Research and Innovation Horizon 2020 under Grant Agreement No 721385. (http:etn-socrates.eu)

\section{CONFLICT OF INTEREST}

The authors declare that they have no conflict of interest.

\section{OPEN ACCESS}

This article is licensed under a Creative Commons Attribution 4.0 International License, which permits use, sharing, adaptation, distribution and reproduction in any medium or format, as long as you give appropriate credit to the original author(s) and the source, provide a link to the Creative Commons licence, and indicate if changes were made. The images or other third party material in this article are included in the article's Creative Commons licence, unless indicated otherwise in a credit line to the material. If material is not included in the article's Creative Commons licence and your intended use is not permitted by statutory regulation or exceeds the permitted use, you will need to obtain permission directly from the copy- right holder. To view a copy of this licence, visit $h$ ttp://creativecommons.org/licenses/by/4.0/.

\section{SUPPLEMENTARY INFORMATION}

The online version contains supplementary material available at https://doi.org/10.1007/s11837021-05020-2.

\section{REFERENCES}

1. A. Malfliet, S. Lotfian, L. Scheunis, V. Petkov, L. Pandelaers, P.T. Jones, and B. Blanpain, J. Eur. Ceram. Soc. 34, 849. (2017).

2. P. Pistorius, J. South. Afr. Inst. Min. Metall. 104, 417. (2004).

3. J. Zietsman and P. Pistorius, Miner. Eng. 19, 262. (2006).

4. J. Zietsman, PhD Thesis: Interactions between Freeze Lining and Slag Bath in Ilmenite Smelting, (South Africa: University of Pretoria, 2004).

5. C. Wei, J. Chen, B. Welch, and V. Voller, Light Metals 1997 ed. R. Huglen (Warrendale, PA: The Minerals, Metals and Materials Society, 1997), p. 309.

6. H. Kellogg, Trans. Metall. Soc. AIME 239, 1439. (1967).

7. A. Solheim and L. Støen, Light Metals 1997, ed. R. Huglen (Warrendale, PA: The Minerals, Metals and Materials Society, 1997), p. 325.

8. A. Solheim, Light Metals 2011, ed. Lindsay S.J (Warrendale, PA: The Minerals, Metals and Materials Society, 2011), p 381.

9. K. Verscheure, $\mathrm{PhD}$ Thesis: Reactor integrity in pyrometallurgical zinc recycling processes, (Belgium: KU Leuven, 2007).

10. M. Campforts, $\mathrm{PhD}$ Thesis: The formation of freeze linings: a microstructural perspective, (Belgium: KU Leuven, 2009)

11. A. Fallah-Mehrjardi, PhD Thesis: Investigation of freezelining formation in metallurgical systems, (Australia: The University of Queensland, 2013).

12. T. Crivits, PhD Thesis: Fundamental studies on the chemical aspects of freeze linings, (Australia: The University of Queensland, 2016).

13. Z. Liu, L. Chen, B. Blanpain, and M. Guo, ISIJ Int. 58, 1972. (2018).

14. Antoon Paar, High temperature viscometer and rheometer: FRS, https://www.anton-paar.com/be-en/products/details/fu rnace-rheometer-systems-frs-1600-and-frs-1800/. Accessed (2020).

15. Fiji, ImageJ Docs, https://imagej.net/software/fiji/. Accessed 2020.

16. H. Shi, L. Chen, A. Malfliet, T.P. Jones, B. Blanpain, and M. Guo, Rheological Behavior of Fayalite Based Secondary Copper Smelter Slag in Iron Saturation. Paper presented at the 10th International Conference on Molten Slags, Fluxes and Salts, Seattle, 22-25 (2016).

17. Z. Liu, L. Zhang, B. Blanpain and M. Guo J. Non-Cryst, Solids 493, 65. (2018).

18. Z. Liu, L. Pandelaers, B. Blanpain, and M. Gou, ISIJ Int. 57, 1895. (2017).

Publisher's Note Springer Nature remains neutral with regard to jurisdictional claims in published maps and institutional affiliations. 